\title{
BRIEF
}

\section{An Innovation Sprint to Promote Problem-solving and Interprofessional Skills Among Pharmacy and Public Health Students}

\author{
Jessica S. Kruger, PhD, ${ }^{a}$ Fred Doloresco, PharmD, MS, ${ }^{\mathrm{b}}$ Jaime Maerten-Rivera, PhD, ${ }^{\mathrm{b}}$ Michelle L. Zafron, \\ MLS, ${ }^{\mathrm{c}}$ Hadar Borden, ${ }^{\mathrm{d}}$ Nicholas M. Fusco, PharmD ${ }^{\mathrm{b}}$ \\ ${ }^{\text {a }}$ University at Buffalo, School of Public Health and Health Professions, Buffalo, New York \\ ${ }^{\mathrm{b}}$ University at Buffalo, School of Pharmacy and Pharmaceutical Sciences, Buffalo, New York \\ ${ }^{\mathrm{c}}$ University at Buffalo University Libraries, Buffalo, New York \\ ${ }^{\mathrm{d}}$ University at Buffalo Blackstone LaunchPad, Buffalo, New York
}

Corresponding Author: Nicholas M. Fusco, University at Buffalo, School of Pharmacy and Pharmaceutical Sciences, 216 Pharmacy Building, Buffalo, NY 14214-8033. Tel: 716-645-1732. Email: nmfusco@buffalo.edu

Submitted August 17, 2021; accepted January 26, 2022; ePublished January 2022

Objective. Innovation sprints are a novel pedagogy where small groups of students find creative solutions to problems. The purpose of this study was to extend our understanding of innovation sprint pedagogical design by investigating the impact of an innovation sprint on pharmacy (PharmD) and public health (MPH) students' interprofessional (IP) collaboration and problem-solving skills. We hypothesized that the innovation sprint would increase student self-efficacy and that IP collaborative behaviors would be demonstrated by individuals on a team.

Methods. MPH and professional year 3 PharmD students were assigned to teams and participated in a required two-hour innovation sprint. Faculty observed student teams and evaluated their IP collaboration skills using a rubric modeled after the Modified McMaster-Ottawa scale. Students completed a post-program survey assessing their IP collaborative behaviors and attitudes toward the innovation sprint.

Results. Of the 133 students participating in the innovation sprint, 127 completed the post-program survey (response rate $=95 \%)$. Faculty determined 123 students $(92 \%)$ met the IP collaboration competencies. The mean interprofessional collaborative competencies attainment survey scores increased for both PharmD and MPH students. Qualitative analyses highlighted themes of IP collaboration and problem-solving skills that students valued. Overall, students enjoyed working with each other and engaging in creative problem-solving.

Conclusion. An IP innovation sprint involving PharmD and MPH students demonstrated a positive impact on student self-assessed IP collaboration and problem-solving skills. Further, faculty observed a high rate of IP behaviors within student teams. Based on these findings, an innovation sprint may be an effective pedagogical tool to enhance students' skills in these areas.

Keywords: interprofessional education, innovation sprint, problem-solving, teamwork, collaboration

\section{INTRODUCTION}

Innovation is a key outcome of personal and professional development within pharmacy curricula, ${ }^{1,2}$ and thus Schools and Colleges of pharmacy are tasked with fostering creative thinking and problem-solving skills. The required and recommended elements of pharmacy education are extensive and time to nurture these skills is limited., Additionally, opportunities for interdisciplinary problem-solving may be lacking. ${ }^{5}$ Therefore, collaboration with other health professions enhance pharmacy students' problem-solving skills while also developing interprofessional (IP) skills like communication and teamwork.

Innovation sprints are a novel pedagogy where small, diverse groups of students find creative solutions to problems. ${ }^{6}$ Innovation sprints are modeled after "hackathons," which are 24-hour to week-long events originally developed to solve technological issues, now seen as a way to accelerate innovation in pharmacy. ${ }^{5}$ Innovation sprints typically follow a sequence of events including orientation to the problem, brainstorming, and culminating with a solution or "pitch." The pitch presentation is delivered to experts in the field who provide feedback. Innovation sprints can be an opportunity for students to practice problem-solving, teamwork, and communication skills.

Innovation sprints could benefit students of pharmacy and other health professions in several ways. They encourage problem-solving, innovation, entrepreneurship, interprofessionalism and teamwork, fulfilling the American Council of Pharmacy Education (ACPE) Standards and Center for the Advancement of Pharmacy Education (CAPE) Outcomes. ${ }^{1,2}$ Additionally, innovation sprints could be a novel approach to IP education (IPE). IPE is a requirement of 
most health professions curricula and should include experiences ensuring health professions students graduate proficient in Interprofessional Education Collaborative (IPEC) core competencies. ${ }^{7,8}$

The University at Buffalo School of Pharmacy and Pharmaceutical Sciences partnered with the School of Public Health and Health Professions and University Libraries to design an IP innovation sprint for Doctor of Pharmacy (PharmD) and Master of Public Health (MPH) students. The purpose of this study was to investigate the impact of an innovation sprint on students' IP collaboration and problem-solving skills. We hypothesized that the innovation sprint would enhance student self-assessed IP and problem-solving skills, and students would demonstrate IP collaborative behaviors to faculty observers.

\section{METHODS}

The IRB determined this study as exempt. Year 3 PharmD and MPH students were required to participate in the innovation sprint for course credit during Fall 2020. Students were organized into teams of three PharmD students and one MPH student. The following challenge statement was provided: "How might we increase medication adherence among low-income patients?" Prior to the activity, students watched a video introducing the innovation sprint (4 minutes), explored the library guide ( 20 minutes), and watched a video on creative problem-solving (4 minutes). The library guide was prepared by a health sciences librarian (MZ) as an online repository of references on medication adherence and preparing a pitch presentation.

Teams were scheduled for a one-time, 120-minute virtual meeting in the evening. The agenda is outlined in Table 1. During the final 30-minutes, students worked on pitch presentations in a separate virtual meeting room and recorded the session. Teams submitted the recording to faculty, who evaluated their interprofessional skills using a based on the Modified McMaster-Ottawa scale. This instrument was developed to assess individual student performance on a team within an IP experience, using a yes/no scale. ${ }^{9}$ The rubric assessed four areas based on the IPE competency domains: values and ethics, roles and responsibilities, communication, and teamwork. ${ }^{7,8}$ Students were deemed to have met all domains if faculty recorded yes to each competency area.

Students completed a post-program survey after the experience. The survey consisted of 39 items including: five demographic questions, the IP Collaborative Competency Attainment Survey (ICCAS), seven retrospective pre- and postrating questions related to the affective domain (ACPE Standards 3 and 4), and seven questions evaluating the program. A previous study has validated the use of ICCAS and demonstrated that the use of the retrospective design does not subject it to social desirability or response shift bias. ${ }^{10}$

The ICCAS is a 20-item, seven-point Likert scale instrument developed to self-assess IP collaborative behaviors based on established IP competencies in six domains: communication, collaboration, roles and responsibilities, collaborative patient/family-centered approach, conflict management/resolution, and team functioning. ${ }^{11}$ The reliability and validity of the instrument has been examined and supports using the instrument for measuring self-report retrospective pre- and post- IP education intervention competency attainment. ${ }^{12,13}$ In addition, the researchers developed seven items related to the affective domain (ACPE Standards 3 and 4) which used the retrospective pre- and postexperience rating and seven-point Likert identical to the ICCAS. The items were worded to reflect the intention of the outcomes in ACPE Standards 3 and 4 but avoided profession-specific language. The wording of these items was reviewed and approved by MPH faculty (JK). Two optional open-ended questions were asked: "What did you enjoy about the innovation sprint?" and "What would you change about the innovation sprint?"

The pre- and post-program ICCAS domain score, affective domain item score and total affective domain scale score for each student were reported as means. Use of the mean of the items, as opposed to the summated score, makes the scores easier to interpret. ${ }^{13}$ The mean and standard deviation (SD) pre- and post-experience scores, along with the mean and SD of the differences were examined by student group (ie, PharmD and MPH).

Paired sample t tests were conducted to examine differences between pre- and post-experience scores. The Cohen's d effect size was computed for each comparison. ${ }^{14}$ Paired sample t-tests were conducted separately for each student group because preliminary analyses suggested that the two student groups differed on many of the variables examined. Reliability was estimated for scale scores using Cronbach $\alpha$. Ideally, Cronbach $\alpha$ reliabilities of 0.90 or above are desired but not below 0.70, which indicates that the items may not be measuring the same underlying construct. ${ }^{15}$ All statistical analyses were conducted using SPSS Statistics 24 (IBM Corp., Armonk, NY).

There were five questions evaluating the overall program, using a five-point Likert scale ( $1=$ strongly disagree to $5=$ strongly agree). The frequencies, percentages, means, and standard deviations were calculated for each item. A thematic analysis approach was used. ${ }^{16}$ Two authors established themes based on a subset of responses. Then the two authors independently reviewed the open-ended responses and coded based on the themes, adding additional themes of needed; discrepancies in codes were discussed until agreement was reached. The number and percent of responses coded for each theme was computed. Specific comments were presented as examples. 


\section{RESULTS}

A total of 133 students participated in the innovation sprint, with 127 students completing the post-program survey (response rate $=95 \%$ ). More MPH students $(40 \%)$ had previously participated in an innovation sprint compared to PharmD students $(1 \%)(p<.001)$. More PharmD students $(100 \%)$ had completed at least one required IPE experience in their professional training compared to MPH students $(57 \%, p<.001)$.

A total of $123(92 \%)$ students met all core competency domains. Of the $10(8 \%)$ students, all PharmD students did not meet all the core competency domains, most (7 of 10) did not contribute to their group's work except for speaking briefly during the final pitch presentation. The remaining ( 3 of 10) did not speak at all.

Comparisons of pre- and post-experience ICCAS scores are summarized in Table 2. The overall trend in mean ICCAS score increases were from a mean corresponding to "slightly agree" at pre- to a mean corresponding to "moderately agree" at the post-test. Similarly, prior to the innovation sprint, all students responded that they "slightly agree" they displayed behaviors related to the affective domain (Table 2). The overall trend in score increases were from a mean corresponding to "slightly agree" at pre- to a mean corresponding to "moderately agree" at the post-test. The Cronbach $\alpha$ at pre-experience were 0.95 and 0.90 and at post-experience was 0.98 and 0.87 for PharmD and MPH students, indicating high reliability.

The items evaluating the innovation sprint experience are summarized in Table 3a. Mean total scale scores (out of 5) for PharmD (M=4.0 SD=1.1) and MPH (M=4.1 SD=0.9) students' evaluation of the innovation sprint experience were high. The themes derived from open-ended programmatic evaluation questions are summarized in Table $3 b$. Overall, students enjoyed working with students from other professions and engaging in creative problem-solving. Opportunities to improve the learning experience centered around organization, duration of experience, and adding more professions.

\section{DISCUSSION}

An IP innovation sprint involving PharmD and MPH students positively impacted students' self-assessed IP collaboration and problem-solving skills. A high percentage of students demonstrated IP collaborative behaviors as evaluated by faculty. Additionally, students rated the experience highly and qualitative analyses further support the themes of IP teamwork, communication, and problem-solving. Based on these findings, an innovation sprint may be an effective pedagogical tool to enhance students' IP collaboration and problem-solving skills.

Fostering innovation and entrepreneurship in pharmacy education can be challenging. ${ }^{3,4}$ Schools and colleges of pharmacy have diverse approaches to addressing ACPE Standards 3 and 4. Students may be exposed to these concepts through student professional organizations, ${ }^{17,}{ }^{18}$ elective courses,${ }^{19}$ or co-curricular activities. ${ }^{20}$ Mogul et al. reported on a co-curricular activity, modeled after the popular television series SharkTank. ${ }^{20}$ Students $(n=38)$ were assigned teams and tasked with developing a solution (or pitch) to a pharmacy services related problem. Faculty evaluated students using a standardized rubric and students completed a pre- and post-program survey. The authors found that students performed better in more basic areas of the challenge and performed worse with higher-level activities. ${ }^{20}$ These findings are important in understanding where students may need additional training or guidance within the problem-solving process. Our data complement these results with a larger sample of students from multiple professional programs. Additionally, we analyzed two other important sources of data: student self-assessed demonstration of IP competencies through the ICCAS instrument and, faculty assessment of individual student performance on the team using the Modified McMaster-Ottawa Scale. Our data revealed that students' self-efficacy as it relates to interprofessional skills increased, and a high percentage of students demonstrated interprofessional behaviors in all core competency domain areas. Of note, the magnitude of effect was primarily small across almost all measures for PharmD students but primarily large for MPH students. This is most likely due to more pharmacy students having participated in required IPE experiences and, pharmacy students having more exposure to experiential education due to the timing of their field training.

The structure of the innovation sprint closely models the process of "design thinking" which has recently been advocated for to promote creative problem-solving in schools and colleges of pharmacy. ${ }^{21}$ The "design thinking" process includes three phases: inspiration, ideation, and implementation. During the innovation sprint, student teams were provided with a challenge statement (inspiration), guided through the creative problem-solving process (ideation), and created their final pitch or solution (implementation). Our data indicate that the innovation sprint had positive effect on students' attitudes related to creative problem-solving and may be a pedagogical tool that mirrors "design thinking."

Study strengths included a large sample size, use of validated instruments, and a concrete exercise that links to both the affective domain of ACPE Standards and IP collaboration core competencies. Study limitations included the onetime activity with one cohort of students. Results could differ with a different challenge statement or other professional students. The innovation sprint was hosted virtually, and it is unclear if findings would be similar if the event was hosted in-person. Although an advantage of the ICCAS instrument is its retrospective pre/post design, this design may introduce 
recall and social desirability bias. ${ }^{22}$ Additionally, at pre-experience both PharmD and MPH students rated themselves highly (mean $>5$ on a 7-point scale) using the ICCAS, which is not uncommon among IPE evaluation instruments but can affect the magnitude of change observed. ${ }^{22}$ Violato et al. noted that this effect size could be due to overconfidence on the students part or a student's lack of baseline knowledge. ${ }^{23}$ In future innovation sprints, the timeframe could be increased, along with the number of professions. Students are familiar with virtual meeting platforms, yet there may be an element of fatigue with this technology, especially when sessions run late into the evening.

\section{CONCLUSION}

An IP innovation sprint involving PharmD and MPH students demonstrated a positive impact on student selfassessed IP collaboration and problem-solving skills. Further, faculty observed a high rate of IP behaviors within student teams. An innovation sprint may be an effective pedagogical tool to enhance students' skills in these areas.

\section{REFERENCES}

1. Accreditation Council for Pharmacy Education. Accreditation standards and key elements for the professional program in pharmacy leading to the doctor of pharmacy degree. https://www.acpeaccredit.org//pdf/Standards2016FINAL.pdf. Accessed August 6, 2021.

2. Medina MS, Plaza CM, Stowe CD, et al. Center for the Advancement of Pharmacy Education 2013 educational outcomes. Am J Pharm Educ. 2013;77(8):Article 162. https://doi.org/10.5688/ajpe778162.

3. Brazeau G. Entrepreneurial spirit in pharmacy. Am J Pharm Educ. 2013;77(5):Article 88. https://doi.org/10.5688/ajpe77588.

4. Fjortoft N. The Challenge of the Accreditation Council for Pharmacy Education's Standard Four: Identifying, Teaching, Measuring. Am J Pharm Educ. 2016;80(5):Article 73. https://doi.org/10.5688/ajpe80573.

5. Aungst TD, Patel R, Pugliese R, Patel I, Boutari C. From ideation to practice: How pharmacists and students can leverage hackathons and innovation labs to accelerate innovation in pharmacy. J Am Pharm Assoc (2003). 2019;59(2S):S25-S29. https://doi.org/10.1016/j.japh.2018.12.009.

6. Knapp J, Zeratsky J, Kowitz B. Sprint: How to solve big problems and test new ideas in just five days. 1st edition. New York, NY: Simon \& Schuster; 2016.

7. Interprofessional Education Collaborative Expert Panel. Core competencies for interprofessional collaborative practice: Report of an expert panel. https://ipec.memberclicks.net/assets/2011-Original.pdf. Accessed August 6, 2021.

8. Interprofessional Education Collaborative Expert Panel. Core competencies for interprofessional collaborative practice: 2016 update. https://ipec.memberclicks.net/assets/2016-Update.pdf. Accessed August 6, 2021.

9. Lie DA, Richter-Lagha R, Forest CP, Walsh A, Lohenry K. When less is more: validating a brief scale to rate interprofessional team competencies. Med Educ Online. 2017;22(1):1314751. https://doi.org/10.1080/10872981.2017.1314751.

10. Kruger JS, Kruger DJ, Ohtake PJ. Validation of the Interprofessional Collaborative Competency Attainment Survey retrospective pre-test measures. Oral Presentation at: NEXUS Summit 2021; October, 2021. Virtual.

11. MacDonald C, Archibald D, Trumpower D, et al. Designing and operationalizing a toolkit of bilingual interprofessional education assessment instruments. Journal of Research in Interprofessional Practice and Education. 2010;1(3):304-316. http://dx.doi.org/10.22230/jripe.2010v1n3a36.

12. Archibald D, Trumpower D, MacDonald CJ. Validation of the interprofessional collaborative competency attainment survey (ICCAS). J Interprof Care. 2014;28(6):553-558.

https://doi.org/10.3109/13561820.2014.917407.

13. Schmitz CC, Radosevich DM, Jardine P, MacDonald CJ, Trumpower D, Archibald D. The Interprofessional Collaborative Competency Attainment Survey (ICCAS): A replication validation study. J Interprof Care. 2017;31(1):28-34. https://doi.org/10.1080/13561820.2016.1233096.

14. Cohen J. Statistical power analysis for the behavioural sciences. 2nd edition. New York, NY: Academic Press; 1988.

15. Kline P. The Handbook of Psychological Testing. 2nd edition. London: Taylor \& Francis; 2000.

16. Castleberry A, Nolen A. Thematic analysis of qualitative research data: Is it as easy as it sounds? Curr Pharm Teach Learn. 2018;10(6):807-815. https://doi.org/10.1016/j.cptl.2018.03.019.

17. Gettig JP, Fjortoft N. Mapping pharmacy student learning during cocurricular activities to national standards and institutional outcomes. Am J Pharm Educ. 2020;84(11):Article 7825. https://doi.org/10.5688/ajpe7825. 
18. Zeeman JM, Bush AA, Cox WC, McLaughlin JE. Assessing the co-curriculum by mapping student organization involvement to curricular outcomes using mixed methods. Am J Pharm Educ. 2019;83(10):Article 7354. https://doi.org/10.5688/ajpe7354.

19. Cain J. A pharmacy elective course on creative thinking, innovation, and TED talks. Am J Pharm Educ. 2016;80(10):Article 170. https://doi.org/10.5688/ajpe8010170.

20. Mogul A, Laughlin E, Lynch S. A co-curricular activity to introduce pharmacy students to the concepts of innovation and entrepreneurship. Am J Pharm Educ. 2020;84(8):Article 7805. https://doi.org/10.5688/ajpe7805.

21. Wolcott MD, McLaughlin JE. Promoting creative problem-solving in schools of pharmacy with the use of design thinking. Am J Pharm Educ. 2020;84(10):Article 8065. https://doi.org/ 10.5688/ajpe8065.

22. Tona J, Kruger J, Jacobsen LJ, et al. Assessing the assessment: a comparison of the IPASS and ICCAS to measure change in interprofessional competencies following a large-scale interprofessional forum [published online ahead of print, 2021 Jan 13]. J Interprof Care. 2021:1-10. https://doi.org/ 10.1080/13561820.2020.1806219.

23. Violato EM, King S. A validity study of the Interprofessional Collaborative Competency Attainment Survey: An interprofessional collaborative competency measure. J Nurs Educ. 2019;58(8):454-462. https://doi.org/10.3928/01484834-20190719-04.

Table 1. Agenda for Interprofessional Innovation Sprint with Pharmacy and Public Health Students

\begin{tabular}{lll}
\hline Agenda Item & Description & Time (min) \\
\hline Welcome & Plenary & 5 \\
Background / Setting the Stage & Plenary & 10 \\
Overview of Creative Problem-Solving Process & Plenary & 15 \\
Ideate, Vote, Build Consensus & Breakout & 15 \\
Introduction to Convergent Tool & Plenary & 5 \\
Teams Complete Convergent Tool & Breakout & 30 \\
Introduction to Pitch Deck & Plenary & 5 \\
Teams Complete Pitch Deck & Breakout & 30 \\
\hline
\end{tabular}


Table 2. Comparison of Pre- and Post-Innovation Sprint Interprofessional Collaborative Competency Attainment Scale (ICCAS) Scores for and Items Related to the Affective Domain PharmD (n=97) and MPH (n=30) Students

\begin{tabular}{|c|c|c|c|c|c|c|}
\hline & $\begin{array}{l}\text { Pre } \\
\text { M }(S D)\end{array}$ & $\begin{array}{l}\text { Post } \\
\text { M (SD) }\end{array}$ & $\begin{array}{l}\text { Difference } \\
M(S D)^{c}\end{array}$ & $p$ & Cohen's d & $\begin{array}{l}\text { Magnitude of } \\
\text { Effect }^{\mathrm{d}}\end{array}$ \\
\hline \multicolumn{7}{|l|}{ ICCAS Subscales } \\
\hline \multicolumn{7}{|l|}{ Communication $^{\mathrm{a}}$} \\
\hline PharmD (pre $\alpha=.93$, post $\alpha=.96$ ) & $5.5(0.9)$ & $5.9(1.1)$ & $0.4(0.8)$ & $<.001 *$ & 0.51 & medium \\
\hline MPH (pre $\alpha=.80$, post $\alpha=.87$ ) & $5.5(0.8)$ & $6.2(0.6)$ & $0.7(0.7)$ & $<.001$ & 1.02 & large \\
\hline \multicolumn{7}{|l|}{ Collaboration $^{\mathrm{a}}$} \\
\hline PharmD (pre $\alpha=.86$, post $\alpha=.93$ ) & $5.4(0.9)$ & $5.9(1.1)$ & $0.5(0.9)$ & $<.001 *$ & 0.52 & medium \\
\hline MPH (pre $\alpha=.85$, post $\alpha=.81)$ & $5.4(1.0)$ & $6.1(0.8)$ & $0.7(0.8)$ & $<.001 *$ & 0.91 & large \\
\hline \multicolumn{7}{|l|}{ Roles and Responsibilities ${ }^{\mathrm{a}}$} \\
\hline PharmD (pre $\alpha=.91$, post $\alpha=.95)$ & $5.5(0.9)$ & $5.9(1.1)$ & $0.4(0.9)$ & $<.001 *$ & 0.43 & small \\
\hline MPH (pre $\alpha=.81$, post $\alpha=.81)$ & $5.7(0.8)$ & $6.3(0.6)$ & $0.6(0.6)$ & $<.001$ & 1.01 & large \\
\hline \multicolumn{7}{|c|}{ Collaborative Patient/Family-Centered Approach ${ }^{\mathrm{a}}$} \\
\hline PharmD (pre $\alpha=.90$, post $\alpha=.90)$ & $5.5(0.9)$ & $5.8(1.1)$ & $0.3(0.8)$ & $<.001 *$ & 0.41 & small \\
\hline MPH (pre $\alpha=.81$, post $\alpha=.85$ ) & $5.2(1.1)$ & $6.1(0.7)$ & $0.9(0.8)$ & $<.001 *$ & 1.06 & large \\
\hline \multicolumn{7}{|l|}{ Conflict Management/Resolution ${ }^{\mathrm{a}}$} \\
\hline PharmD (pre $\alpha=.90$, post $\alpha=.90)$ & $5.7(0.9)$ & $5.9(1.2)$ & $0.3(0.9)$ & $.008 *$ & 0.28 & small \\
\hline MPH (pre $\alpha=.80$, post $\alpha=.80)$ & $5.9(0.8)$ & $6.3(0.8)$ & $0.5(0.6)$ & $<.001 *$ & 0.75 & medium \\
\hline \multicolumn{7}{|l|}{ Team Functioning $^{\mathrm{a}}$} \\
\hline PharmD (pre $\alpha=.92$, post $\alpha=.97$ ) & $5.5(1.0)$ & $5.9(1.2)$ & $0.3(1.1)$ & $.002 *$ & 0.32 & small \\
\hline MPH (pre $\alpha=.87$, post $\alpha=.90)$ & $5.6(0.9)$ & $6.3(0.7)$ & $0.7(0.8)$ & $<.001 *$ & 0.85 & large \\
\hline \multicolumn{7}{|c|}{ Items Related to the Affective Domain } \\
\hline \multicolumn{7}{|c|}{ Recognize social determinants of health that impact health disparities ${ }^{b}$} \\
\hline PharmD & $5.5(0.9)$ & $5.9(1.1)$ & $0.4(1.1)$ & $.001 *$ & 0.35 & small \\
\hline MPH & $6.2(0.8)$ & $6.7(0.5)$ & $0.5(0.6)$ & $<.001 *$ & 0.74 & medium \\
\hline \multicolumn{7}{|c|}{ Describe how population-based care influences patient-centered care ${ }^{\mathrm{b}}$} \\
\hline PharmD & $5.5(1.0)$ & $5.9(1.1)$ & $0.4(1.1)$ & $.001 *$ & 0.35 & small \\
\hline MPH & $6.0(1.0)$ & $6.5(0.8)$ & $0.5(0.6)$ & $<.001 *$ & 0.74 & medium \\
\hline \multicolumn{7}{|l|}{ Identify problems ${ }^{\mathrm{b}}$} \\
\hline PharmD & $5.6(1.1)$ & $5.9(1.2)$ & $0.4(1.1)$ & $.002 *$ & 0.32 & small \\
\hline $\mathrm{MPH}$ & $6.2(0.8)$ & $6.6(0.6)$ & $0.5(0.7)$ & $.001 *$ & 0.69 & medium \\
\hline \multicolumn{7}{|c|}{ Explore and prioritize potential strategies to address a problem ${ }^{\mathrm{b}}$} \\
\hline PharmD & $5.6(1.0)$ & $5.9(1.1)$ & $0.4(1.1)$ & $.001 *$ & 0.34 & small \\
\hline MPH & $5.8(1.0)$ & $6.4(0.9)$ & $0.6(0.7)$ & $<.001 *$ & 0.84 & large \\
\hline \multicolumn{7}{|c|}{ Design a viable solution to a problem ${ }^{\mathrm{b}}$} \\
\hline PharmD & $5.5(1.0)$ & $5.9(1.1)$ & $0.4(1.1)$ & $<.001 *$ & 0.37 & small \\
\hline
\end{tabular}


Table 3. Summary of PharmD $(n=97)$ and MPH $(n=30)$ Students' Evaluation of the Innovation Sprint

\begin{tabular}{|c|c|c|c|c|c|c|c|}
\hline \multicolumn{8}{|l|}{ 3a. Summary of Quantitative Items } \\
\hline & $\begin{array}{l}\text { Strongly } \\
\text { Disagree } \\
\text { n }(\%) \\
\end{array}$ & $\begin{array}{l}\text { Disagree } \\
\text { n }(\%)\end{array}$ & $\begin{array}{l}\text { Neutral } \\
\text { n }(\%)\end{array}$ & $\begin{array}{l}\text { Agree } \\
\text { n }(\%)\end{array}$ & $\begin{array}{l}\text { Strongly } \\
\text { Agree } \\
\text { n }(\%) \\
\end{array}$ & $\begin{array}{l}\text { Missing } \\
\text { n }(\%)\end{array}$ & M (SD) \\
\hline \multicolumn{8}{|c|}{ I think that doing this activity was useful for development of attributes of teamwork (e.g., communication, commitment, sharing ideas, responsibility). } \\
\hline PharmD & $5(5.2)$ & $1(1.0)$ & $15(15.5)$ & $29(29.9)$ & $47(48.5)$ & $0(0.0)$ & $4.15(1.06)$ \\
\hline MPH & $0(0.0)$ & $2(6.7)$ & $5(16.7)$ & $8(26.7)$ & $15(50.0)$ & $0(0.0)$ & $4.20(0.96)$ \\
\hline \multicolumn{8}{|c|}{ I would recommend this activity for other students } \\
\hline PharmD & $6(6.2)$ & $4(4.1)$ & $17(17.5)$ & $30(30.9)$ & $40(41.2)$ & $0(0.0)$ & $3.97(1.15)$ \\
\hline MPH & $1(3.3)$ & $2(6.7)$ & $7(23.3)$ & $8(26.7)$ & $12(40.0)$ & $0(0.0)$ & $3.93(1.11)$ \\
\hline \multicolumn{8}{|c|}{ This experience added value to my professional development } \\
\hline PharmD & $6(6.2)$ & $5(5.2)$ & $17(17.5)$ & $28(28.9)$ & $40(41.2)$ & $1(1.0)$ & $3.95(1.17)$ \\
\hline MPH & $0(0.0)$ & $3(10.0)$ & $8(26.7)$ & $7(23.3)$ & $12(40.0)$ & $0(0.0)$ & $3.93(1.05)$ \\
\hline \multicolumn{8}{|c|}{ The innovation sprint helped me learn about creative problem solving. } \\
\hline PharmD & $7(7.2)$ & $2(2.1)$ & $14(14.4)$ & $33(34.0)$ & $41(42.3)$ & $0(0.0)$ & $4.02(1.14)$ \\
\hline MPH & $0(0.0)$ & $0(0.0)$ & $7(23.3)$ & $10(33.3)$ & $13(43.3)$ & $0(0.0)$ & $4.20(0.80)$ \\
\hline \multicolumn{8}{|c|}{ This experience helped prepare me to be a future health professional. } \\
\hline PharmD & $6(6.2)$ & $4(4.1)$ & $20(20.6)$ & $26(26.8)$ & $40(41.2)$ & $1(1.0)$ & $3.94(1.17)$ \\
\hline MPH & $0(0.0)$ & $1(3.3)$ & $4(13.3)$ & $13(43.3)$ & $12(40.0)$ & $0(0.0)$ & $4.20(0.80)$ \\
\hline \multicolumn{8}{|l|}{ 3b. Summary of Qualitative Items } \\
\hline & Theme & $\begin{array}{l}\text { PharmD } \\
\text { n }(\%)^{\mathrm{a}}\end{array}$ & $\begin{array}{l}\text { MPH } \\
\text { n }(\%)^{a}\end{array}$ & \multicolumn{4}{|c|}{ Sample comments } \\
\hline $\begin{array}{l}\text { What about this learning experience did you } \\
\text { enjoy most? }\end{array}$ & Collaboration & $22(39)$ & $12(46)$ & \multicolumn{4}{|c|}{$\begin{array}{l}\text { I enjoyed collaborating with other healthcare students and } \\
\text { coming up with innovating solutions to real healthcare } \\
\text { problems. }\end{array}$} \\
\hline \multirow[t]{2}{*}{$\begin{array}{l}\text { PharmD n=56 } \\
\text { MPH n=26 }\end{array}$} & $\begin{array}{l}\text { Interaction with } \\
\text { other professions }\end{array}$ & $14(25)$ & $6(23)$ & \multicolumn{4}{|c|}{$\begin{array}{l}\text { I enjoyed seeing the public health student's perspective of } \\
\text { the problem and solution. }\end{array}$} \\
\hline & $\begin{array}{l}\text { Creative } \\
\text { problem-solving }\end{array}$ & $11(20)$ & $5(19)$ & \multicolumn{4}{|c|}{$\begin{array}{l}\text { I liked the creative problem-solving portion where no idea } \\
\text { is a bad idea - it's an effective way to get a lot of ideas to } \\
\text { work through and can be applied to a broad range of } \\
\text { problems. }\end{array}$} \\
\hline $\begin{array}{l}\text { What would improve this learning } \\
\text { experience? }\end{array}$ & & & & \multirow{2}{*}{\multicolumn{4}{|c|}{$\begin{array}{l}\text { Less back and forth between break out rooms. Zoom } \\
\text { Fatigue is real. } \\
\text { Less time spent on brainstorming and more on explaining } \\
\text { the assignment. }\end{array}$}} \\
\hline $\begin{array}{l}\text { PharmD n=56 } \\
\text { MPH n }=24\end{array}$ & $\begin{array}{l}\text { Organization of } \\
\text { sprint }\end{array}$ & $17(30)$ & $4(16)$ & & & & \\
\hline
\end{tabular}


Timing of the

Sprint:

General $(\mathrm{G})$

Longer (L)

Shorter (S)

Include students

from other

professions
The scheduled time can be changed because 6-8 pm may not be ideal. $(\mathrm{G})$

It would be better if we could have more time to work

through the problem. (L)

I would keep the duration shorter as people tend to lose concentration around the 45 minutes mark. (S)

S: 2 (8)

Perhaps having more students from different healthcare professionals to learn about their perspectives. 